\title{
Isolated facial nerve palsy: Rare manifestation of dengue haemorrhagic fever A case report
}

\author{
ARM Misthaq ${ }^{1}$, S Pirasath $^{1}$, AGH Sugathapala ${ }^{1}$ \\ Sri Lankan Journal of Infectious Diseases 2019 Vol.9 (1):95-97 \\ DOI: http://dx.doi.org/10.4038/sljid.v9i1.8237
}

\begin{abstract}
Dengue is a common arboviral infection and is one of the tropical diseases which occur in Sri Lanka. Neurological manifestations due to dengue are very rare but can be caused by serotypes 2 and 3. Here we report of an isolated facial nerve palsy occurring as a manifestation of dengue haemorrhagic fever (DHF) in a young boy who presented with fever and constitutional symptoms. Haematological parameters were suggestive of dengue with dengue IgM being positive. Subsequently, he developed right side lower motor neuron type of facial nerve palsy. He was treated with a high dose of steroids and facial nerve stimulation therapy. He clinically recovered without residual weakness.
\end{abstract}

Keywords: Dengue fever, Facial nerve palsy, Lower motor neuron

\section{Introduction}

Dengue is a common arboviral infection and is among the tropical diseases which occur in Sri Lanka. Dengue virus has four serotypes. Neurological manifestations are very rare and are caused by serotypes 2 and 3. ${ }^{1}$ Encephalopathy, meningitis, acute pure motor weakness, mononeuropathies, transverse myelitis, stroke, acute disseminated encephalomyelitis, GuillainBarre Syndrome, hypokalemic paralysis and neuromyelitis optica are the recognized neurological manifestations associated with dengue fever. ${ }^{2}$ There were few cases of isolated facial nerve palsy in dengue haemorrhagic fever which had been reported in literature in Sri Lanka. ${ }^{3}$ Here we report of an isolated facial nerve palsy occurring as a manifestation of dengue haemorrhagic fever in a young boy.

\section{Case report}

A previously healthy 18 year old boy presented with fever, myalgia, arthralgia and headache of 3 days duration. He had no other systemic symptoms. On examination, he was febrile and flushed. His pulse rate was $92 /$ minute and blood pressure $100 / 60 \mathrm{mmHg}$ without postural drop. He had no

${ }^{1}$ Colombo South Teaching Hospital, Kalubowila, Sri Lanka.

Address for correspondence: Dr. Selladurai Pirasath, Colombo South Teaching Hospital, Kalubowila, Sri Lanka Telephone: +94775122995 Email: selladuraipirasath81@gmail.com (iD) https://orcid.org/0000-0002-4274-4919

Received 24 December 2018 and revised version accepted 17 March 2019 
evidence of leakage on admission. His initial full blood count showed leukopenia $\left(3250 / \mathrm{mm}^{3}\right)$ with predominant lymphocytes $(36 \%)$ and thrombocytopenia $\left(96,000 / \mathrm{mm}^{3}\right)$. His NS 1 antigen was positive on day 3 and dengue IgM antibody was positive on day 7 . On the $6^{\text {th }}$ day, his platelet count dropped to $56,000 / \mathrm{mm}^{3}$ with a raised packed cell volume (42\% to $48 \%$ ). His white cell count dropped to $2840 / \mathrm{mm}^{3}$ (neutrophils $-45 \%$, lymphocytes $-42 \%$ ). His liver enzymes were high (AST - 78 IU/1, ALT - 62 IU/l) but renal function tests were normal. His ultrasound showed moderate ascites and pleural effusion suggestive of the critical phase of dengue fever.

He was managed according to the national guidelines of dengue haemorrhagic fever published by the Ministry of Health, Sri Lanka. ${ }^{4}$ He improved clinically, and platelet counts returned to normal limits.

On the $8^{\text {th }}$ day, in recovery phase, he developed deviation of his mouth to the left side, difficulty in closing his right eye and wrinkling of the right side of his forehead. He had no limb weakness, facial numbness, swallowing difficulty, double vision, unsteady gait, earache or parotid swelling. On neurological examination, he had a right sided lower motor neuron type of facial nerve palsy. His nerve conduction study confirmed the diagnosis. Imaging of his brain was normal and inflammatory markers and autoimmune screening were negative. His work up for viral etiology (HSV, EBV and retroviral screening) was negative.

The patient was treated with prednisolone $1 \mathrm{mg} / \mathrm{kg} / \mathrm{day}$ for 10 days and facial nerve stimulation therapy. He was followed up at the clinic and he recovered without residual weakness at 4 weeks.

The timeline of the patient's clinical course is shown below.

Timeline of clinical progression

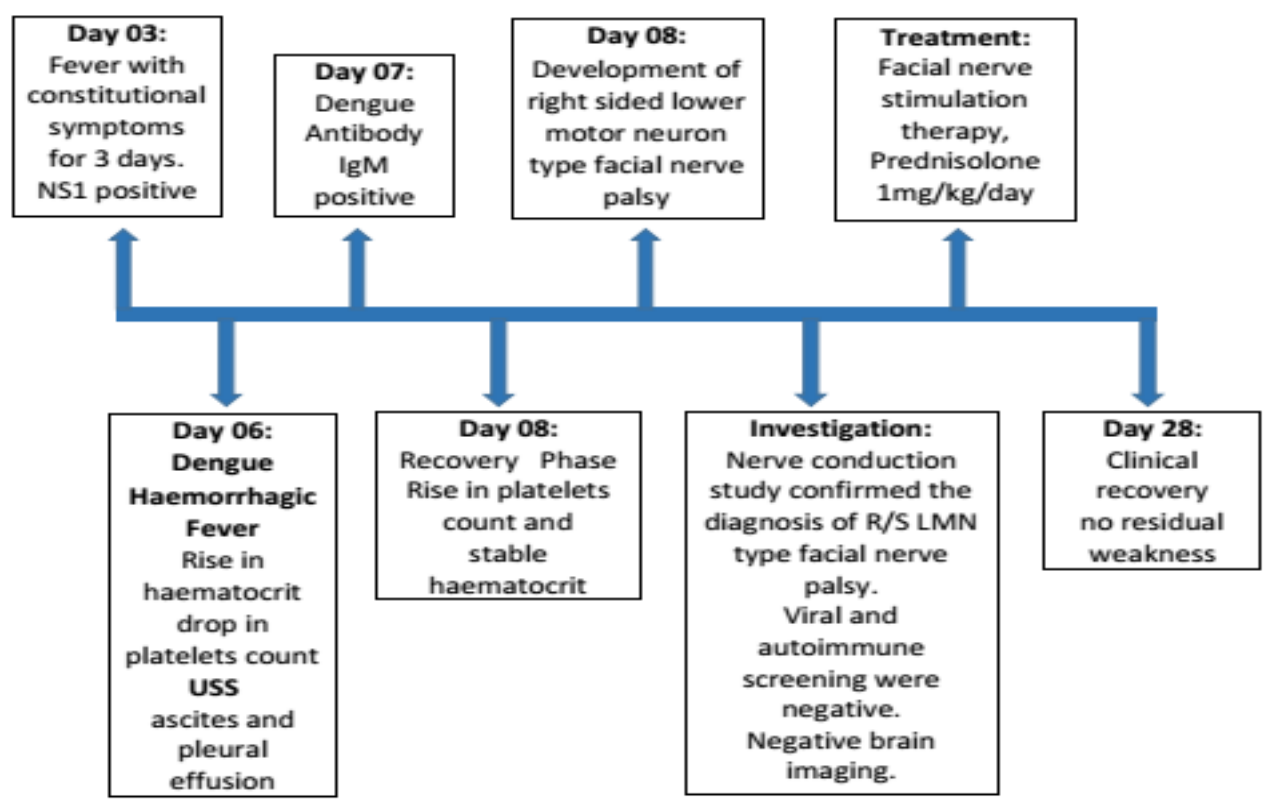




\section{Discussion}

Dengue is the most commonly encountered arboviral disease among tropical diseases in Sri Lanka. Neurological manifestations in dengue are a rare phenomenon but the incidence of unusual presentations and complications of this common viral infection is on the rise. Neurological manifestations are very rare and are usually seen with serotypes 2 and 3 . $^{1}$ Neurological signs were first described in 1976 as atypical symptoms of dengue infection. ${ }^{5}$ The pathogenesis of neurological complications and the contribution of viral and host factors are not well understood but can be related to neurotrophic effects of the virus, systemic effects of the infection or can even be immune mediated. ${ }^{6}$

The neurological complications of dengue virus infection are classified into three categories: metabolic disturbances (encephalopathy), viral invasion (encephalitis, meningitis, myositis, and myelitis) and autoimmune reactions (acute disseminated encephalomyelitis, neuromyelitis optica, optic neuritis, myelitis, encephalopathy, and Guillain-Barre syndrome). ${ }^{2}$

Dengue is gradually becoming a major public health problem worldwide. A growing number of related studies will increase awareness and understanding of the neurological complications of dengue infection. Physicians will continue to play important roles in its diagnosis and treatment. A high level of suspicion can lead to rightful early diagnosis and prompt timely management leading to a significant improvement in mortality and morbidity in cases of neurological complications due to dengue. It should be considered as a cause for lower motor neuron type facial nerve palsy in an endemic area in clinical practice.

Conflict of Interest: Authors declare no conflict of interest

Ethics: Informed and written consent for publication was obtained from the patient

\section{References}

1. Chowdhury RN, Siddiqui MR, Mahbub MS, et al. Dengue fever as a cause of acute disseminated encephalomyelitis (ADEM). J Medicine 2011; 12:185-187.

doi: https://doi.org/10.3329/jom.v12i2.8428

2. Murthy JM. Neurological complication of dengue infection. Neurol India 2010; 58:581-4. doi: https://doi.org/10.4103/0028-3886.68654

3. Sunantha S, Peranantharajah T, Nisahan B. Isolated lower motor neuron type facial nerve palsy: An unusual manifestation of dengue haemorrhagic fever. Jaffna Medical Journal 2018; 30(1):35.6. doi: http://doi.org/10.4038/jmj.v30i1.11

4. Ministry of Health, Sri Lanka. National guidelines. Guidelines on management of dengue fever $\&$. dengue haemorrhagic fever.

http://www.epid.gov.lk/web/images/pdf/Publication/guidelines_for_the_management_of_df_and_ dhf_in_adults.pdf

5. Sanguansermsri T, Poneprasert B, Phornphutkul B, et al. Acute encephalopathy associated with dengue infection. Bangkok: SEAMEO TROPMED; 1976. No doi

6. Domingues R. B., Kuster G. W. Diagnosis and management neurologic manifestations associated with acute dengue virus infection. J. Neuroinfect. Dis 2014; 5:138

doi: https://doi: 10.4172/2314-7326.1000138. 